\title{
Prospective Study of Holter Monitoring in Pediatric Patients at Sohag University Hospital
}

\author{
Safaa Ali*, Feby Sobhy, Mohamed Abd El Aal, Shiamaa Mahamoud \\ Sohag University Hospital, Sohag, Egypt \\ Email: ^safaah003@gmail.com,dr.feby.safwat@gmail.com, mohamed_1370@hotmail.com, shiamaahaafy512@yahoo.com
}

How to cite this paper: Ali, S., Sobhy, F., El Aal, M.A. and Mahamoud, S. (2020) Prospective Study of Holter Monitoring in Pediatric Patients at Sohag University Hospital. World Journal of Cardiovascular Diseases, 10, 460-472.

https://doi.org/10.4236/wjcd.2020.107046

Received: May 14, 2020

Accepted: July 24, 2020

Published: July 27, 2020

Copyright $\odot 2020$ by author(s) and Scientific Research Publishing Inc. This work is licensed under the Creative Commons Attribution International License (CC BY 4.0).

http://creativecommons.org/licenses/by/4.0/ (c) (i)

\begin{abstract}
Background: To estimate the various indications, values and misuses of Holter monitoring in the diagnosis and management of pediatric patients. Methods: The study was a prospective observational study, carried out at Pediatric Arrhythmia Clinic and at PICU of Sohag University Hospital over two years from 09/2017 to 09/2019. It encountered 80 pediatric patients ( 34 females), their age ranged from 29 days to 15 years with mean age of 6.18 years. All patients were subjected to echocardiography, 12 leads ECG and holter monitoring for 24 hours. Minimum, mean, maximum heart rate, rhythms and corrected QT were evaluated. Indications of Holter examination, its abnormalities were analyzed, also its positive diagnosis and management were defined. Results: Palpitations and syncopy were the main indications for holter examination $22(27.50 \%)$ patients for each, abnormal examination in 17 (21.25\%), chest pain in 13 patients (16.25\%) and cardiomyopathy (7.5\%) (one with Hypertrophic Cardiomyopathy and five with Dilated Cardiomyopathy). There were $50(62.50 \%)$ patients had abnormalities in Holter recordings. The highest contribution to diagnosis was in cardiomyopathy (83.3\%) where the most common abnormalities were ventricular tachycardia (50\%) and ventricular premature beats in (33.3\%). An abnormal ECG was significantly associated with a higher diagnostic yield $(\mathrm{p}=0.0001)$. Conclusion: The most important indications for Holter monitoring include palpitations, syncope, abnormal physical exam findings, chest pain, and cardiomyopathy. Holter monitoring is an extremely important tool in the assessment of patients with dilated cardiomyopathy. HM detects serious arrhythmias to identify patients who are at increased risk for subsequent morbid events. The abnormal ECG findings were associated with having an abnormal Holter, therefore Holter monitoring can be used to help select which patients should get this screening tool especially in low budget programs countries.
\end{abstract}

\section{Keywords}

Holter, Pediatric, Arrhythmia, ECG 


\section{Introduction}

More than 4 decades of clinical experience have shown long-term ECG to be one of the most effective noninvasive clinical tools in the diagnosis and assessment of cardiac symptoms, prognostic assessment or risk stratification of various cardiac populations and in the evaluation of many cardiac therapeutic interventions. It remains an indispensable and highly refined tool for cardiac rhythm analysis and risk prediction [1].

The clinical utility of ambulatory ECG lies in its ability to examine continuously a patient over an extended period of time, permitting patient ambulatory activity and facilitating the diurnal electrocardiographic examination of a patient in a changing environmental milieu (both physical and psychological) [2].

However, the value of Holter monitoring in capturing brief symptomatic episodes of conduction system disorders is limited by the fact that they have to occur often enough to be captured during the 24-hour period of recording. Holter technology was proven to be a valuable adjunctive non-invasive diagnostic technology to record the ambulatory long term ECG [3].

Despite its vast application in adult patients, studies in the paediatric age group are limited. The present work aimed to study the various indications, values and misuses of Holter monitoring in the diagnosis and management of pediatric patients.

This study included 80 pediatric patients who were recruited from pediatric arrhythmia clinic and PICU at Sohag University Hospital. Their age ranged from 29 days to 15 years with mean age of 6.18 years.

\section{Patients and Methods}

The study was prospective observational study that carried out at Pediatric Arrhythmia Clinic and at PICU of Sohag University Hospital over two years from September2017 to September 2019. An informed oral and written consent was taken from the caregivers of children included in the study. The study approved by Ethical Scientific Committee at Sohag Faculty of Medicine for approval.

\section{Inclusion criteria:}

Any child undergoes Holter monitoring was included in the study.

The patients were referred for the following indications:

1) Screening for arrhythmias in patients with: syncope, palpitations, chest pain, WPW, and abnormality on examination (rapid, slow, irregular heart).

2) Follow up of patients with frequent ventricular ectopics (VE) and on antiarrhythmic therapy.

3) In children with complete heart block, a decision needs to be made about their need for pacing. A lot of indications for pacing as stated by the AHA can be deduced from 24 hour HM. These include the presence of long pauses, the minimum heart rate and the presence of non benign arrhythmias.

4) Patients with cardiomyopathy (dilated, hypertrophic and restrictive).

\section{Methods:}


All patients in this study were subjected to the following:

1) Echocardiography: the following echocardiographic variables were recorded

- Normal echocardiography.

- Congenital heart disease.

- Picture of myocarditis: Echocardiography demonstrates four-chamber dilation with poor ventricular function and $\mathrm{AV}$ valve regurgitation. A pericardial effusion may be present.

- Abnormalities of coronary artery (ALCAPA, coronary fistula, aneurysm).

2) 12 leads ECG: 12 leads ECG was done to all infants \& children before having Holter monitoring using (FUKUDA DENSHI, CARDIMAX, model FCP-7101). 12 leads ECG Record analyzed using specific centile tables for normal values of ECG waves \& intervals according to age [4].

3) Holter monitoring.

Duration: 24 hours.

Type of machine: Mortara 2016 american made H3+.

Software: Mortara Company American made.

Holter monitoring was applied to all children, minimum, mean, maximum heart rate, rhythms and corrected QT were evaluated.

Positive contribution of Holter was identified as:

1) Diagnosis: Establishing a new diagnosis/changing a current diagnosis/confirming a suspected diagnosis.

2) Management: Introducing new therapy/withdrawal of current therapy/change of current dosage of therapy.

\section{Analysis:}

All Holter recorders were subsequently analyzed. This analysis system uses a feature extraction system to group individual QRS complexes based on their features and utilizes technician interaction in arrhythmia analysis aided by visual superimposition to correct for artefact and any erroneous analysis.

Arrhythmia detected either by ECG or Holter according to specific arrhythmia definitions as reported by George and his colleagues [5].

\section{Statistical analysis}

Data was analyzed using STATA version 14.2 (Stata Statistical Software: Release 14.2 College Station, TX: StataCorp LP.). Quantitative data was represented as mean, standard deviation, median and range. Data was analyzed using student t-test to compare means of two groups and ANOVA for comparison of the means of three groups or more and least significance difference (LSD) post hoc test. When the data was not normally distributed Kruskal Wallis test for comparison of three or more groups and Mann-Whitney test was used to compare two groups.

\section{Results}

The median age of the 80 included patients ( 34 females and 46 males) was 6 years ranging from 29 days to 15 years. The family history of CHD was negative 
in 74 children (92.5\%). 22 (27.5\%) patients had palpitation, $22(27.50 \%)$ patients with syncopy, 17 (21.25\%) patients had abnormal examination, 13 (16.25\%) patients had chest pain and $6(7.5 \%)$ patients had cardiomyopathy (one with HCM and five with DCM) Table 1.

There were 22 patients complaining of palpitation, the ECG was normal in 11 patients, one patient had heart block, 6 patients had sinus tachycardia, 3 patients had ectopics and one patient had WPWS pattern.

Also there were 22 patients with Syncope, the ECG was normal in 13 patients, 4 patients had heart block, one patient had sinus bradycardia and 4 patients had ectopic.

17 Patients with abnormal examination which include irregular HR (heart block \& ectopics), tachycardia and bradycardia.

The ECG was normal in one patient, 3 patients had heart block, 8 patients had sinus bradycardia, 3 patients had sinus tachycardia and 2 patients had ectopics.

There were 13 patients with chest pain, the ECG was normal in 8 patients, 3 patients had heart block and 2 patients had ectopics.

There were 6 patients with cardiomyopathy (5 DCM \& 1 Hypertrophic cardiomyopathy), the ECG was normal in 2 patients, one patient had sinus bradycardia and 3 patients had ectopics Table 2.

There were $30(37.50 \%)$ patients their Holter was normal, 8 (10\%) patients had sinus bradycardia, 9 (11.25\%) patients had sinus tachycardia, 2 (2.5\%) patients had atrial ectopic, 3 (3.75\%) patients had junctional ectopic, 13 (16.25\%) patients had ventricular ectopics, $4(5 \%)$ patients had $1^{\text {st }}$ degree heart block, 1 $(1.25 \%)$ patients had $2^{\text {nd }}$ degree heart block, $2(2.50 \%)$ patients had $3^{\text {rd }}$ degree heart block, 3 (3.75\%) patients had SVT, 1 (1.25\%) patient had WPWS pattern and $4(5 \%)$ patients had ventricular tachycardia Table 3.

Table 1. Demographic data and indication of the studied population.

\begin{tabular}{cc}
\hline Variable & Summary statistics \\
\hline Age/year & $6.18 \pm 4.11$ \\
Mean \pm SD & $6(0.08: 15)$ \\
Median (range) & \\
Gender & $34(42.5 \%)$ \\
Female & $46(57.5 \%)$ \\
Male & \\
Family history of CHD & $74(92.5 \%)$ \\
Negative & $6(7.5 \%)$ \\
Positive & Number (\%) \\
Indication & $22(27.5)$ \\
Palpitation & $22(27.5)$ \\
Syncope & $17(21.25)$ \\
Abnormal examination & $13(16.25)$ \\
Chest pain & $6(7.5)$ \\
Cardiomyopathy & \\
\hline
\end{tabular}


Table 2. ECG finding by complaint.

\begin{tabular}{cccc}
\hline Indication & Number & ECG finding & Number (\%) \\
\hline \multirow{3}{*}{ Palpitation } & Normal & $11(50)$ \\
& \multirow{2}{*}{22} & Heart block & $1(4.6)$ \\
& Tachycardia & $6(27.3)$ \\
& Ectopics & $3(13.6)$ \\
Syncope & WPW & $1(4.6)$ \\
& & Normal & $13(59.1)$ \\
& \multirow{2}{*}{22} & Heart block & $4(18.2)$ \\
& & Bradycardia & $1(4.6)$ \\
Abnormal examination & Ectopics & $4(18.2)$ \\
& & Normal & $1(5.9)$ \\
& & Heart block & $3(17.7)$ \\
& & Bradycardia & $8(47.1)$ \\
Chest pain & Tachycardia & $3(17.7))$ \\
& & Ectopics & $2(11.8)$ \\
& & Normal & $8(61.5)$ \\
& & Heart block & $3(23.1)$ \\
& & Ectopics & $2(15.4))$ \\
& & Normal & $2(33.3)$ \\
& & Bradycardia & $1(16.7))$ \\
& & Ectopics & $3(50)$ \\
& & &
\end{tabular}

$\mathrm{WPW}=$ Wolf Parkinson White Syndrome.

Table 3. Holter finding of studied population.

\begin{tabular}{cc}
\hline Holter finding & Number (\%) \\
\hline Normal & $30(37.5)$ \\
Sinus bradycardia & $8(10)$ \\
Sinus tachycardia & $9(11.25)$ \\
Atrial ectopics & $2(2.5)$ \\
Junctional ectopics & $3(3.75)$ \\
Ventricular ectopics & $13(16.25)$ \\
1st degree HB & $4(5)$ \\
2nd degree HB & $1(1.25)$ \\
3rd degree HB & $2(2.5)$ \\
SVT & $3(3.75)$ \\
WPW & $1(1.25)$ \\
Ventricular tachycardia & $4(5)$ \\
\hline
\end{tabular}

$\mathrm{HB}=$ Heart Block. SVT $=$ Supra-ventricular tachycardia.WPW $=$ Wolf Parkinson White Syndrome.

There were 22 patients with palpitation, the holter recording was normal in 11 patients, 4 patients had sinus tachycardia, 3 patients had ventricular ectopics, one patient had 2 nd degree heart block, 2 patients had SVT and one patient had WPWS pattern.

There were 22 patients with Syncope, the holter recording was normal in 8 patients, one patient had sinus bradycardia, another one patient had sinus ta- 
chycardia, 2 patients had atrial ectopic, one patient had junctional ectopic, 5 patients had ventricular ectopics, 3 patients had $1^{\text {st }}$ degree heart block and one patient had ventricular tachycardia (diagnosed by stress ECG as catecholaminergic ventricular tachycardia).

There were 17 Patients with abnormal examination which include irregular HR (heart block \& ectopics), tachycardia and bradycardia

The holter recording was normal in 2 patients, 6 patients had sinus bradycardia, 3 patients had sinus tachycardia, one patient had junctional ectopic, one patient had ventricular ectopics, one patient had $1^{\text {st }}$ degree heart block, 2 patients had 3rd degree heart block and one patients had SVT.

There were 13 patients with chest pain, the holter recording was normal in 9 patients one patient had sinus tachycardia, one patient had junctional ectopic and 2 patients had ventricular ectopics.

There were 6 patients with cardiomyopathy (5 DCM \& 1 Hypertrophic cardiomyopathy), all patients with cardiomyopathy had abnormal holter finding. Their Holter recording showed that one patient had sinus tachycardia, 2 patients had ventricular ectopics and 3 patients had ventricular tachycardia Table 4, Figure 1.

Table 4. Holter findings by common indication.

\begin{tabular}{|c|c|c|c|}
\hline Indication & Number & Holter finding & Number (\%) \\
\hline \multirow{6}{*}{ Palpitation } & \multirow{6}{*}{22} & Normal & $11(50)$ \\
\hline & & Sinus tachycardia & $4(18.2)$ \\
\hline & & Ventricular ectopic & $3(13.7)$ \\
\hline & & 2nd degree HB & $1(4.6)$ \\
\hline & & SVT & $2(9.1)$ \\
\hline & & WPW & $1(4.6)$ \\
\hline \multirow{8}{*}{ Syncope } & \multirow{8}{*}{22} & Normal & $8(36.4)$ \\
\hline & & Sinus bradycardia & $1(4.6)$ \\
\hline & & Sinus tachycardia & $1(4.6)$ \\
\hline & & Atrial ectopic & $2(9.1)$ \\
\hline & & Junctional ectopic & $1(4.6)$ \\
\hline & & Ventricular ectopic & $5(22.7)$ \\
\hline & & 1st degree HB & $3(13.6)$ \\
\hline & & Ventricular tachycardia & $1(4.6)$ \\
\hline \multirow{8}{*}{ Abnormal examination } & \multirow{8}{*}{17} & Normal & $2(11.8)$ \\
\hline & & Sinus bradycardia & $6(35.3)$ \\
\hline & & Sinus tachycardia & $3(17.7)$ \\
\hline & & Junctional ectopic & $1(5.9)$ \\
\hline & & Ventricular ectopic & $1(5.9)$ \\
\hline & & 1st degree $\mathrm{HB}$ & $1(5.9)$ \\
\hline & & 3rd degree HB & $2(11.8)$ \\
\hline & & SVT & $1(5.9)$ \\
\hline \multirow{4}{*}{ Chest pain } & \multirow{4}{*}{13} & Normal & $9(69.2)$ \\
\hline & & Sinus tachycardia & $1(7.7)$ \\
\hline & & Junctional ectopic & $1(7.7)$ \\
\hline & & Ventricular ectopic & $2(15.4)$ \\
\hline \multirow{3}{*}{ Cardiomyopathy } & \multirow{3}{*}{6} & Sinus tachycardia & $1(16.7)$ \\
\hline & & Ventricular ectopic & $2(33.3)$ \\
\hline & & Ventricular tachycardia & $3(50)$ \\
\hline
\end{tabular}

$\mathrm{HB}=$ Heart Block. SVT $=$ Supra-ventricular tachycardia.WPW $=$ Wolf Parkinson White Syndrome. 


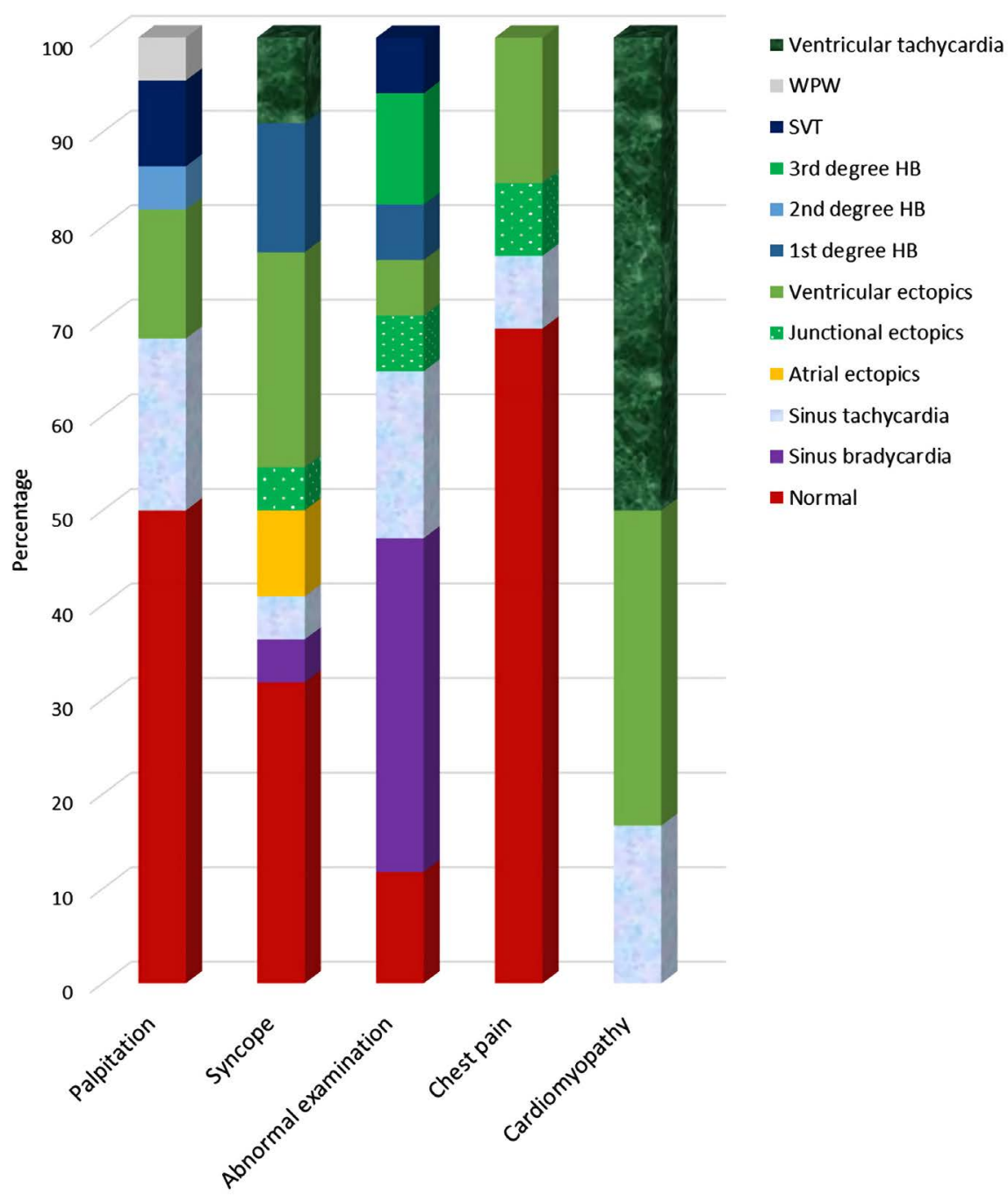

Figure 1. Holter findings by complaint. $\mathrm{HB}=$ Heart Block. SVT $=$ Supra-ventricular tachycardia.WPW = Wolf Parkinson White Syndrome.

Of the 22 patients with palpitation holter was useful in diagnosis of $5(22.73 \%)$ patients and was useful in management of 4 (18.18\%) patients.

Of the 22 patients with syncope, Holter was useful in diagnosis of $10(45.45 \%)$ patients and was useful in management of 7 (31.82\%) patients.

Of the 17 patients with abnormal examination Holter was useful in diagnosis of $6(35.29 \%)$ patients and was useful in management of 4 (23.53\%) patients.

Of the 13 patients with chest pain Holter was useful in diagnosis of $4(30.77 \%)$ patients and was useful in management of $2(15.38 \%)$ patients.

Of the 6 patients with cardiompopathy ECG was useful in diagnosis of 5 $(83.33 \%)$ patients and was useful in management of 2 (33.33\%) patients Table 5, Figure 2.

Eighty-four\% of patients who had abnormal ECG had abnormal Holter recording, with astatically significant difference between patients who had normal ECG and abnormal ECG regarding positive abnormality in Holter.

Holter recording was useful in diagnosis of $55 \%$ of patients with astatically 
Table 5. Value of Holter recording in diagnosis and management of studied patients.

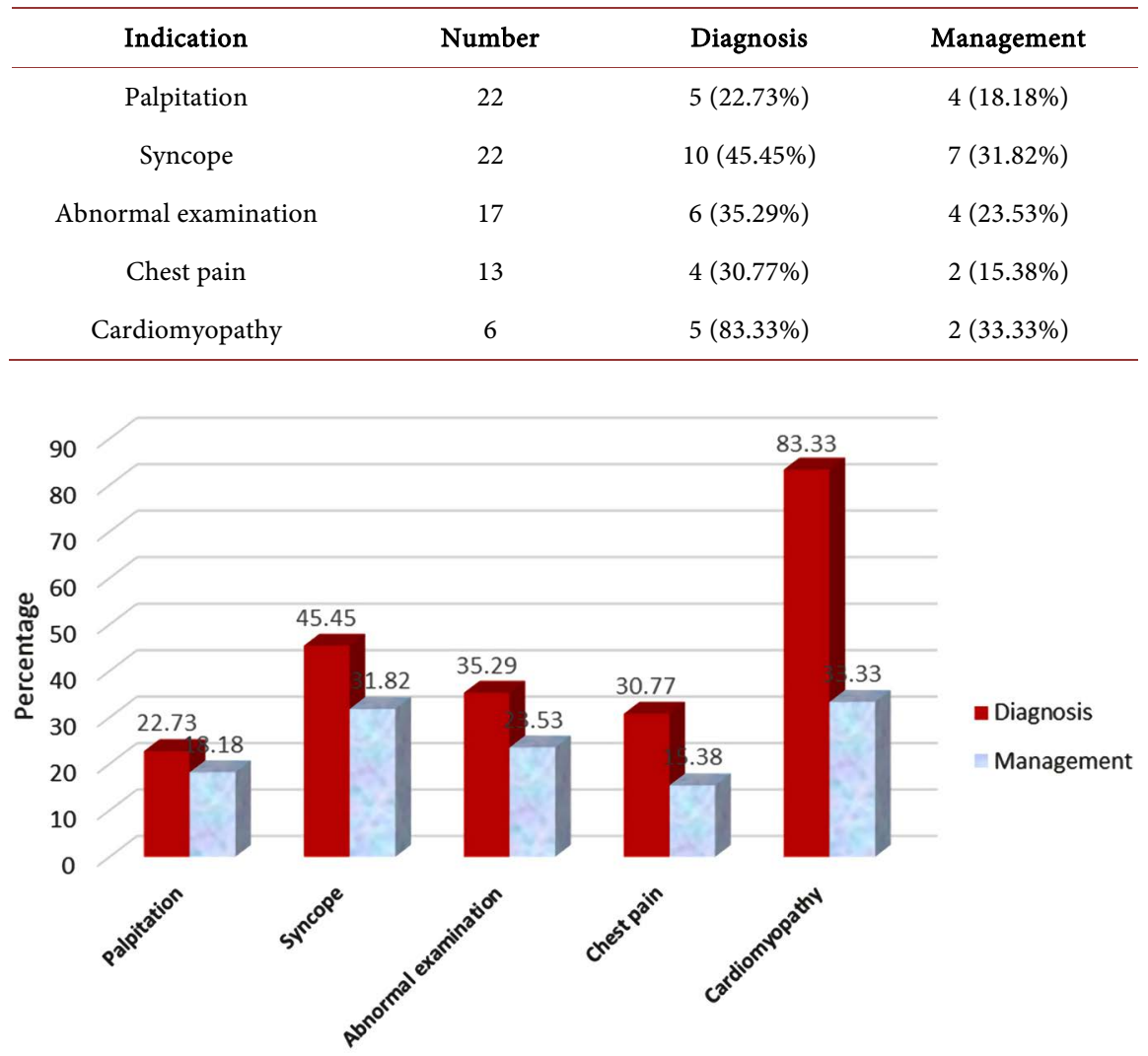

Figure 2. Value of Holter in diagnosis and management.

significant difference between patients who had abnormal Holter and those had normal Holter recording.

Also, Holter recording was useful in management of $36 \%$ of patients with astatically significant difference between patients who had normal \& abnormal Holter recording Table 6

\section{Discussion}

The clinical utility of ambulatory ECG lies in its ability to examine continuously a patient over an extended period of time, permitting patient ambulatory activity and facilitating the diurnal electrocardiographic examination of a patient in a changing environmental milieu (both physical and psychological) [2]. Despite its vast application in adult patients, studies in the pediatric age group are limited. The present work aimed to study the various indications, values and misuses of Holter monitoring in the diagnosis and management of pediatric patients.

The present study conducted 80 pediatric patients who were recruited from Pediatric Arrhythmia Clinic and PICU at Sohag University Hospital their age range was 29 days to 15 years with mean age of 6.18 years. 46 (57.5\%) males and $34(42.5 \%)$ females. The main indications for Holter monitoring of these patients were palpitation \& syncope. These results agree with findings of many literatures [6] [7]. 
Table 6. Relation between abnormality in ECG and positive abnormality in Holter, positive diagnosis and positive management.

\begin{tabular}{cccc}
\hline Variable & $\begin{array}{c}\text { Abnormal ECG } \\
\mathrm{N}=45\end{array}$ & $\begin{array}{c}\text { Normal ECG } \\
\mathrm{N}=35\end{array}$ & P value \\
\hline Positive abnormalities in Holter & $38(84.4 \%)$ & $14(40 \%)$ & $<0.0001$ \\
Variable & $\begin{array}{c}\text { Abnormal Holter } \\
\mathrm{N}=52\end{array}$ & $\begin{array}{c}\text { Normal Holter } \\
\mathrm{N}=28\end{array}$ & P value \\
Positive diagnosis & $29(55.8 \%)$ & $1(3.6 \%)$ & $<0.0001$ \\
Positive management & $19(36.5 \%)$ & 0 & $<0.0001$ \\
\hline
\end{tabular}

The most common indication for Holter examination in our cohort patients was the evaluation of palpitaion. In this study there were 22 patients with palpitation, the Holter recording demonstrated abnormalities in 11 patients; four had sinus tachycardia, three had ventricular ectopic, one had 2nd degree heart block, two had SVT and one had WPWS pattern, with a diagnostic yield of $22.73 \%$ of patients and an percentage of $18.18 \%$ had a change of management. This in concordance with large study of Holter examination in 1319 pediatric patients conducted by Hegazy, et al. that demonstrated that the commonest indication in their study was the evaluation of palpitation. $8.8 \%$ of their examined recordings revealed abnormalities, out of which $\mathrm{n}=15$ (5.7\%) of diagnoses were established solely on and $n=17$ (6.5\%) had a change of their management. These patients had a higher percentage of pauses, SVE, VE and HB than those who presented with other symptoms. Ayabakan et al. study that recommended the one of the primary indications of AECG monitoring was to exclude arrhythmias as the cause of palpitations [6] [7].

The current study reported 22 patients with Syncope, their Holter recording was normal in 8 patients, one patient had sinus bradycardia, another one patient had sinus tachycardia, 2 patients had atrial ectopic, one patient had junctional ectopic, 5 patients had ventricular ectopic, 3 patients had $1^{\text {st }}$ degree heart block and one patient had ventricular tachycardia, with a diagnostic yield of $45.45 \%$ of patients and an percentage of $31.82 \%$ had a change of management. Cardiac arrhythmias should be considered among the malignant causes of syncope in children. Hence, syncope is a common cause of referral for Holter $(27.5 \%, \mathrm{n}=22$ patients) [8]. The low diagnostic yield of Holter in children with syncope had been previously reported [9].

The results of the present study agrees with that of Kilic, et al., who reported a much higher diagnostic yield of AECG, but the highly selective nature of the study population most likely contributed to this fact [10].

Chest pain is a common cause of anxiety among patients and parents and it is one of the most frequent causes of referral to cardiology outpatient clinics. Our results demonstrated 13 cases (16.25\%) with chest pain, the Holter recording was abnormal only in 4 patients; one had sinus tachycardia, one had junctional ectopic and 2 had ventricular ectopic. It with a diagnostic yield of $30.77 \%$ of patients and a percentage of $15.38 \%$ had a change of management. This agrees 
with the findings of Baker, et al. and Hegazy, et al. who documented that chest pain particularly in the absence of organic heart disease, Holter monitoring has little value. The primary role of HM in this case may be to exclude rather than diagnose a cause [11]. Despite large pediatric study by Hegazy et al., demonstrated none of their patients presented with chest pain had abnormal recordings [7].

In the current study there were 6 patients with cardiomyopathy (five with DCM \& one with Hypertrophic cardiomyopathy), all of them had abnormal Holter finding. Their Holter recording showed that one patient had sinus tachycardia, 2 patients had ventricular ectopic and 3 patients had ventricular tachycardia, with a diagnostic yield of $83.33 \%$ of patients and an percentage of $33.33 \%$ had a change of management.

Ambulatory electrocardiography (AECG) provides useful prognostic value in patients with DCM and may identify several independent predictors of mortality including nonsustained VT and mean HR However, 24-hour electrocardiographic monitoring documents a high prevalence of potentially serious arrhythmias in patients with hypertrophic cardiomyopathy. Detection of such arrhythmias may help identify patients who are at increased risk for subsequent morbid events [11].

Our results found that AECG remains an indispensable tool in the regular assessment and risk stratification of children with cardiomyopathy with important implications on their diagnosis and management.

There were two patients who underwent Holter monitoring for evaluation of complete heart block (CHB). Vukomanovic, et al., study determined the significance of HR analysis as a predictive factor for Adams stokes and heart failure in children with CCAVB. They found HM extremely valuable in determining predictive factors for Adams stokes attacks and heart failure in children and adolescents with complete heart block. Nonpaced children need regular Holter monitoring assessments to complete their diagnostic work up and help decision making [12].

Our results found only one patient had WPWS pattern, although the diagnostic assessment and the treatment have been described in patients with symptomatic WPW, the management of asymptomatic subjects remains controversial. Holter monitoring was deemed unnecessary in evaluation of asymptomatic patients with WPW. Usually these patients are assumed to have a benign process, however very occasionally they present with VF as the first manifestation of the syndrome hence the dilemma of how extensively they should be investigated and managed. Despite the fact that Sarubbi, 2006 has been concluded that patients with WPW who develop AF and VF are different from those who don't; noninvasive methods as HM seem to be relatively incomplete for risk stratification [13].

There were 50 patients (62.50\%) had abnormal Holter recordings. 8 (10.00\%) patients had sinus bradycardia, 9 (11.25\%) patients had sinus tachycardia, 2 
(2.5\%) patients had atrial ectopic, 3 (3.75\%) patients had junctional ectopic, 13 (16.25\%) patients had ventricular ectopic, 4 (5.00\%) patients had $1^{\text {st }}$ degree heart block, $1(1.25 \%)$ patients had $2^{\text {nd }}$ degree heart block, $2(2.50 \%)$ patients had $3^{\text {rd }}$ degree heart block, 3 (3.75\%) patients had SVT, 1 (1.25\%) patient had WPWS pattern and $4(5.00 \%)$ patients had ventricular tachycardia. Our results disagree with that of Hegazy et al., that demonstrated 141 patients (10.7\%) had abnormal Holter recordings. 299 patients (22.6\%) had infrequent isolated supraventricular ectopic and 1185 patients (89.9\%) had infrequent isolated ventricular ectopic. These were not considered abnormal [7].

$\mathrm{HM}$ was of positive contribution to diagnose 30 (37.5\%) of our cohort patients and to provide a management in 19 (23.75\%) of patients. This disagrees with Hegazy, et al. study that determine the positive contribution of Holter monitorings was of diagnosis in 144 (10.9\%) of patients and of management in 258 (19.6\%) of patients [6].

In this study $84 \%$ of patients who had abnormal ECG had abnormal Holter recording, with astatically significant difference between patients who had normal ECG and abnormal ECG regarding positive abnormality in Holter. This agrees with Hegazy, et al. study in which 12 lead ECG was performed in 1136 (86.1\%) of patients prior to Holter recordings. Of those 298 (26.2\%) had abnormal ECGs. 77 (49.4\%) of patients with abnormal ECGs had abnormal Holter recordings as compared to 64 (5.6\%) of patients with normal ECG. This result also agrees with Massin, et al., 2005 that documented an abnormal ECG is a clue to increase yield of subsequent Holter monitoring. This is likely due to the fact that patients with structurally abnormal hearts or with cardiac rhythm abnormalities evident on their resting ECG are more likely to have abnormal Holter monitoring [7] [14].

The current study did not encountered children with postoperative arrhythmia due to our hospital had adult cardiac surgery only. Despite large study results by Hegazy et al., [7] revealed the value of HM in postoperative arrhythmia that reported $29.4 \%$ diagnostic yield and $26.5 \%$ in their management. However, their study established the HM is an important non-invasive method for detecting heart rhythm in children after repair of Fallot' tetrology.

The higher percentage of abnormal Holter findings in the present study compared to other studies is probably due to the highly selective nature of the study population. ECG examination is economical compared with the HM that is a major consideration in developing countries with low -budget programs. Thus, we aim to predetermine the usage and indications of HM based on the results of current study and the previous literatures.

\section{Study limitations}

Limitations of the present study include its single center experience and the relatively small number of patients. More studies with a larger number of children and follow up patients with postoperative and post device closure of ASD and VSD assessment is required. 


\section{Conclusion}

The most important indications for Holter monitoring include palpitations, syncope, abnormal physical exam findings, chest pain, and cardiomyopathy. Holter monitoring is an extremely important tool in the assessment of patients with dilated cardiomyopathy. HM detects serious arrhythmias to identify patients who are at increased risks for subsequent morbid events. The abnormal ECG findings were associated with having an abnormal Holter, therefore Holter monitoring can be used to help select which patients should get this screening tool especially in low budget programs countries.

\section{Conflicts of Interest}

The authors declare no conflicts of interest regarding the publication of this paper.

\section{References}

[1] Kennedy, H. (2000) Use of Long-Term (Holter) Electrocardiographic Recordings. In: Zipes, D. and Jalife, J., Eds., Cardiac Electrophysiology from Cell to Bedside, 3rd Edition, WB Saunders, Philadelphia, 717-730.

[2] Kennedy, H. (2006) The History, Science, and Innovation of Holter Technology. Annals of Noninvasive Electrocardiology, 11, 85-94. https://doi.org/10.1111/j.1542-474X.2006.00067.x

[3] Van Hare, G. and Dubin, A. (2001) Electrocardiogram. In: Allen, H., Gutgese II, H., Clarck, E. and Dricsoll, D., Eds., Moss and Adams' Heart Disease in Infants, Children and Adolescents, 6th Edition, Lippincott Williams and Wilkins, Philadelphia, 425-443.

[4] Rijnbeek, R., Witsenburg, M., Schrama, E., Hess, J. and Kors, J.A. (2001) Normal Limits for the Paediatric ECG. European Heart Journal, 22, 702-711.

[5] Van Hare, G.F. (2012) Disturbance of Rate and Rhythm of the Heart. In: Nelson Text Book of Paediatrics, $20^{\text {th }}$ Edition, Elsevier, Amsterdam, 2250-2260.

[6] Ayabakan, C., Ozer, S., Celiker, A. and Ozme, S. (2000) Analysis of 2017 Holter Records in Pediatric Patients. The Turkish Journal of Pediatrics, 42, 286-293.

[7] Hegazy, R.A. and Lotfy, W.N. (2007) The Value of Holter Monitoring in the Assessment of Pediatric Patients. Indian Pacing and Electrophysiology Journal, 7, 204-214.

[8] Streiper, M. (2005) Distinguishing Benign Syncope from Life Threatening Cardiac Causes of Syncope. Seminars in Pediatric Neurology, 12, 32-38.

https://doi.org/10.1016/j.spen.2005.01.001

[9] Fitchet, A., Stirling, M., Burnett, G., Goode, G.K., Garratt, C.J. and Fitzpatrick, A.P. (2003) Holter Monitoring vs Tilt Testing in the Investigation of Suspected Vasovagal Syncope. Pacing and Clinical Electrophysiology, 26, 1523-1527. https://doi.org/10.1046/j.1460-9592.2003.t01-1-00221.x

[10] Kilic, A., Ozer, S., Turanli, G., Ayabakan, C., Celiker, A. and Ozme, S. (2002) Dysrhythmia as a Cause of Syncope in Children without Neurological or Cardiac Morphological Abnormalities. Pediatrics International, 44, 358-362. https://doi.org/10.1046/j.1442-200X.2002.01579.x

[11] Baker, R.L. and Koelling, T.M. (2005) Prognostic Value of Ambulatory Electrocar- 
diography Monitoring in Patients with Dilated Cardiomyopathy. Journal of Electrocardiology, 38, 64-68. https://doi.org/10.1016/j.jelectrocard.2004.09.007

[12] Vukomanovic, V., Stajevic, M., Kosutic, J., Stojanov, P., Rakic, S., Velinovic, M., Sehic, I. and Milovanovic, V. (2007) Age-Related Role of Ambulatory Electrocardiographic Monitoring in Risk Stratification of Patients with Complete Congenital Atrioventricular Block. Europace, 9, 88-93. https://doi.org/10.1093/europace/eul174

[13] Sarubbi, B. (2006) The Wolff-Parkinson-White Electrocardiogram Pattern in Athletes: How and When to Evaluate the Risk for Dangerous Arrhythmias. The Opinion of the Pediatric Cardiologist. Journal of Cardiovascular Medicine (Hagerstown), 7, 271-278. https://doi.org/10.2459/01.JCM.0000219320.97256.4d

[14] Massin, M.M., Bourguignont, A. and Gerard, P. (2005) Study of Cardiac Rate and Rhythm Patterns in Ambulatory and Hospitalized Children. Cardiology, 103, 174-179. https://doi.org/10.1159/000084590

[15] Crawford, M., Bernstein, S., Deedwania, P., et al. (1999) ACC/AHA Guidelines for Ambulatory Electrocardiography. Journal of the American College of Cardiology, 34, 912-948. https://doi.org/10.1016/S0735-1097(99)00354-X

[16] More, S. (2000) CC/AHA Guidelines for Ambulatory ECG. American Family Physician, 61, 884-888.

\section{List of Abbreviations}

$\mathrm{HM}=$ Holter Monitoring.

PICU $=$ pediatric intensive care.

$\mathrm{ECG}=$ Electric cardiogram.

WPW $=$ Wolf Parkinson White Syndrome.

$\mathrm{VE}=$ Ventricular Ectopic.

ALCAPA = Anomalous origin of left coronary artery from pulmonary artery.

$\mathrm{CHD}=$ Congenital heart disease.

$\mathrm{HCM}=$ Hypertrophic cardiomyopathy.

$\mathrm{DCM}=$ Dilated cardiomyopathy.

$\mathrm{HB}=$ heart block.

SVT $=$ supraventricular tachycardia. 